\title{
Biological Parameters of Euschistus heros (F.) (Heteroptera: Pentatomidae) and its Susceptibility to Entomopathogenic Fungi When Fed on Different Diets
}

\author{
Daian Guilherme Pinto Oliveira ${ }^{1 *}$, Amnada Caroline Dudczak ${ }^{2}$, Luis Francisco Angeli \\ Alves ${ }^{2}$, Daniel Ricardo Sosa-Gomez ${ }^{3}$. \\ ${ }^{1}$ Federal University of Technology/UTFPR, Santa Helena, Paraná, Brazil. ${ }^{2}$ State University of Western Paraná, \\ Laboratory of Agricultural Biotechnology, Cascavel, Paraná, Brazil. ${ }^{3}$ Embrapa Soybean Research Center, Londrina, \\ Paraná, Brasil.
}

\begin{abstract}
The effects of six diets on biological parameters of Euschistus heros (F.) (Heteroptera: Pentatomidae) and its susceptibility to entomopathogenic fungi Beauveria bassiana $(\mathrm{Bb})$ and Metarhizium anisopliae (Ma) were studied. The diets included a standard diet (bean pods+soybeans, peanuts and sunflower) and diets in which the bean pods were combined with only one type of grain, either soybean, peanut, sunflower, pea or sesame seeds. The best performance was that of insects fed on standard diet, which had the shortest development period and 49.5\% of egg-to-adult viability. The insects fed the pea diet exhibited less than $30 \%$ viability and $11 \%$ of adults had wing deformations. The finite rate of increase values for the treatment groups were: standard: 1.091; soybean: 1.077; peanut: 1.071; sunflower: 1.076; pea: 1.058; and sesame: 1.065. The susceptibility to $\mathrm{Ma}(55 \%)$ was greater than $\mathrm{Bb}(40 \%)$ only for insects fed on the sesame diet. Considering the effects of diet on susceptibility to both fungal species comparatively among the diet-treatment groups, the stink bugs fed the restrictive diets were more susceptible compared with those fed the standard diet. We concluded that diet composition affects the biological parameters of $\mathrm{E}$. heros and differentially affects their susceptibility to $\mathrm{Bb}$ and $\mathrm{Ma}$ fungi.
\end{abstract}

Key Words: Beauveria bassiana, Tri-trophic interactions, Metarhizium anisopliae, Brown stink bug.

\footnotetext{
${ }^{1}$ Authors for correspondence: daianguilherme@yahoo.com.br
} 


\section{INTRODUCTION}

During the reproductive phase of Soybean (Glycine $\max$ L.) Merrill crops the stink bug incurs its greatest losses and causes both direct and indirect damage to the crops (Panizzi 2013). Among the species most frequently found on soybeans, Euschistus heros (F.) (Heteroptera: Pentatomidae) are considered the most relevant pests in the main productive regions of Brazil (Sosa-Gómez et al. 2009).

The large populations of these insects and the lack of action-level usage of insecticides frequently leads to the indiscriminate use of chemical products to control of these insects (Corrêa-Ferreira 2005). The use of chemical insecticides may result in severe damage to humans and the environment. New strategies with lower impact are utilized within an integrated pest management (IPM) program.

Regarding the use of entomopathogens in IPM strategies, the sucking feeding habit of stink bugs has hindered the use of bacteria, viruses or protozoa (Sosa-Gómez et al. 1998; Ihara et al. 2008). Natural infections of fungi occur in wild populations of stink bugs, which are mainly caused by Beauveria bassiana (Bals) Vuill (Ascomycota: Cordycipitaceae) and Metarhizium anisopliae (Metsch.) Sorok. (Ascomycota: Clavicipitaceae). The incidence of these infections is generally low (Moscardi et al. 1988) and the occurrence of natural epizootics with high prevalence are restricted to greenhouse conditions (Sosa-Gómez et al. 1997).

Studies have been undertaken with the aim of determining the effects of fungal infection on laboratory stink bug populations. The results of these studies demonstrated that high concentrations of conidia are required to reach a satisfactory mortality index (Moscardi et al. 1985; Sosa-Gómez et al. 1997; Sosa-Gómez et al. 1998).

The different species belonging to the soybeanstink bug complex exhibit various levels of susceptibility to entomopathogenic fungi, and some are inherently tolerant to infection by such fungi (Sosa-Gómez et al. 1997).

Little is known about the mechanisms underlying the tolerance of stink bugs to fungi and possible ways of interfering with their susceptibility to these organisms.

Considering the variety of antimicrobial defense strategies of insects, their resistance to fungal infections may have various causes. Particular integument structures, the presence of antifungal compounds in the superficial cuticle layer of the exoskeleton (Ortiz-Urquiza et al. 2013), and humoral or cellular defense reactions may increase the resistance of insects to fungal infections (Vilcinskas et al. 1999).

The susceptibility of phytophagous insects to fungi may also be affected by several factors associated with their host plants. The impact of the insect nutritional status on the development of diseases involves complex mechanisms and multitrophic interactions (Sosa-Gómez 2012). The nutritional intake may affect inoculum production in the cadavers of insects that were killed by pathogens (Cory et al. 2004).

In this study, we examined the effects of different natural diets on the biological parameters of $E$. heros at all life stages and the susceptibility of these stink bugs to the entomopathogenic fungi $B$. bassiana and $M$. anisopliae. Susceptibility was evaluated using mortality bioassays and the length of the conidial germ tubes on the cuticular surface of the insects.

\section{MATERIALS AND METHODS}

\section{E. heros stock breeding and diet evaluation}

Stock breeding was initiated using eggs obtained from a six year colony maintained in the Laboratory of Entomology of Embrapa Soja (state of Paraná, Brazil). Since then, new stink bugs eggs collected in the field have been added annually. The insects were maintained in controlled environment rooms $\left(26 \pm 2^{\circ} \mathrm{C}, 60 \pm 10 \% \mathrm{RH}\right.$ and a 14-hour photoperiod) according to a breeding method modified from Silva et al. (2008). After hatching, the nymphs were stored in covered crystal-polyester $11 \times 11 \times 3 \mathrm{~cm}$ boxes until they reached the $4^{\text {th }}$ instar. The feed for the nymphs included the following: fresh bean pods (Phaseolus vulgaris L.), soybeans, peanuts (Arachis hypogea L.) and sunflower (Helianthus annus L.) seeds. After the nymphs reached the $5^{\text {th }}$ instar, they were transferred to plastic boxes $(16 \mathrm{x}$ $16 \times 25 \mathrm{~cm})$ with mesh on the side and top. In addition to the diet already described, the insects were supplied branches of privet (Ligustrum lucidum Ait.) with fruits. Strips of cotton were provided for egg laying. The laid eggs were transferred to plastic boxes with humidified paper on the bottoms. The previously described environmental conditions were maintained until the eggs hatched.

To form treatment groups, eggs from the breeding stock were separated into plastic boxes with ad 
libitum availability of specific natural diet components. The insects were fed these diets throughout development. The dietary treatments were the following: a) standard (fresh bean pods + soybeans, peanuts and sunflower seeds); b) soybean (fresh bean pods + soybeans); c) peanut (fresh bean pods + peanuts); d) sunflower (fresh bean pods + sunflower seeds); e) pea (fresh bean pods + Pisum sativum L. peas); and f) sesame (fresh bean pods + Sesamum indicum L. sesame seeds).

\section{Comparative biology of $E$. heros treated with natural diets of various composition}

The following biological parameters of the insects were studied: i) egg viability and incubation period; ii) duration of each nymphal instar and partial (per instar) and total viability; and iii) adult weight 48 hours post-emergence, sex ratio, percentage of deformed insects, pre-egg laying, egg laying, and post-egg laying periods, longevity and the number of eggs produced per female (fecundity).

To evaluate the egg-stage parameters, several egg masses randomly obtained from the F1 generation of insects fed each diet were separated into plastic boxes containing humidified filter paper, as previously described. Four replicates of 50 eggs $(n=200)$ each were used for each treatment. Evaluations were performed daily to determine the incubation duration and hatching percentage.

The nymphal study was performed using $E$. heros $2^{\text {nd }}$ instar nymphs derived from several egg masses of the breeding stock. The nymphs were separated into specific treatment groups and maintained in individual plastic boxes in the controlled environment previously described. The experiments included six treatments (diets a, b, c, d, $\mathrm{e}$, and $\mathrm{f}$, described above) with four replicates of 50 to 60 nymphs.

After 24 hours, the nymphs that were killed by handling were discarded, which explains the variability in insect numbers for " $n$ " repetitions of 215, 186, 186, 186, 194 and 228, respectively, for diets a, b, c, d, e, and f. Daily the instar changes were noted, the dead insects were discarded and fresh food was provided until the emergence of adults.

The adults that emerged in each treatment group were sexed, weighed and paired in couples. The adults with deformities were counted. Twenty healthful couples were used for each treatment. Each insect couple was placed in a plastic box and considered a replicate. Eggs on strips of cotton were counted daily. The experiment was continued even after the death of one of the members of the couple to determine the longevity.

A life parameter and fertility table was assembled according to the diet treatment. This table included the following parameters, the values for which were determined according to Silveira Neto et al. (1976): $\lambda$ (finite rate of increase); Ro (net reproductive rate); $\mathrm{rm}$ (intrinsic rate of increase); DT (duplication time) and $\mathrm{T}$ (duration of one generation) and was created using the following data: duration of the period between eggs and adults; cycle viability; pre-egg laying period; sex ratio; daily number of eggs produced per female; and the daily mortality rate of the males and females.

\section{Effect of the diet on the susceptibility of $E$. heros to fungi}

Isolates Unioeste 22 (M. anisopliae) and Unioeste 46 (B. bassiana) from the Agricultural Biotechnology Laboratory collection of Unioeste University (state of Paraná, Brazil), which were previously found to be pathogenic to E. heros, were produced on potato dextrose agar medium (PDA). The fungi were incubated in plates for 7 to 10 days $\left(26 \pm 1{ }^{\circ} \mathrm{C}\right)$ for conidiogenesis. Suspensions of conidia were prepared by adding them to a sterile Tween $80(0.05 \%)$ solution, vortexing for five minutes and sonicating for two minutes. Afterward, serial dilutions were prepared for conidial counts using a Neubauer chamber to standardize the concentrations of suspensions (Alves et al. 1998). The conidial viability had been previously determined according to Oliveira et al. (2015).

The susceptibility of the stink bugs from each diettreatment group to the fungi was determined using two different bioassays, as follows: i) comparison of the mortality caused by the fungal isolates $\left(10^{5}\right.$ conidia per insect) in each diet-treatment group (same diet, B. bassiana $\times M$. anisopliae); and ii) comparison of the mortality caused in each isolate $\left(10^{4}\right.$ conidia per insect) among the diet-treatment groups (same fungi, $\mathrm{a} \times \mathrm{b} \times \mathrm{c} \times \mathrm{d} \times \mathrm{e} \times \mathrm{f}$ diets). The fungi were inoculated $(1 \mu \mathrm{l})$ in the metathoracic articulation of the legs using a glass syringe coupled to an automatic micro-applicator (Bukard Manufacturing Co. Ltd., Uxbridge, UK). The treatment groups included five replicates of 20 unsexed adults (48 hours post-emergence). After inoculation, the insects were maintained in plastic boxes with their specific diets. The treated insects were maintained in BOD-type chambers (at $26 \pm$ $2{ }^{\circ} \mathrm{C}, 60 \pm 10 \% \mathrm{RH}$, with a 14-hour photoperiod) for 
12 days. The mortality was evaluated and fresh food was provided daily. The dead insects were placed in a humid chamber to confirm cause of death.

\section{Germination on the $E$. heros wings}

The average sizes of the germ tubes that developed on the right hind wing of the stink bugs were determined for each diet-treatment group (same fungi, $\mathrm{a} \times \mathrm{b} \times \mathrm{c} \times \mathrm{d} \times \mathrm{e} \times \mathrm{f}$ diets). The wings were placed on glass slides using $5 \mu$ l of water to facilitate adhesion. Conidia suspensions $\left(10^{8} / \mathrm{ml}\right)$ were applied to the wings for 20 seconds using a portable pneumatic nebulizer (Soniclear ${ }^{\circledR}$ ), and the slides containing the wings were placed in humid chamber $\left(26 \pm 2^{\circ} \mathrm{C}\right.$, saturated humidity, and a 14 hour photoperiod). After 24 hours, the average length of the germ tubes was determined using phase-contrast microscopy at $400 \times$ magnification. Twenty germ tubes in each treatment group were imaged using a camera linked to a microscope. Measurements of the germinated conidia located between the subcostal and R1 nervures were performed. The images were later analyzed using the BelView 7 program (BEL Engineering ${ }^{\odot}$, Monza, Italy).

\section{Statistical analyses}

All experiments were conducted using a completely randomized design. The statistical analyses were performed using the programs SAS/STAT (Sas 2003) or ASSISTAT 7.7 (Silva et al. 2006). The

Table 1: Average duration and viability rate of each nymphal instar and the egg-to-adult period for Euschistus heros reared on different natural diets under laboratory conditions $\left(26 \pm 2^{\circ} \mathrm{C}\right.$; RH: $60 \pm 10 \%$; photoperiod: 14 hours).

\begin{tabular}{|c|c|c|c|c|c|c|}
\hline \multirow{2}{*}{ Diet } & \multirow{2}{*}{ Egg stage } & \multicolumn{4}{|c|}{ Nymphal instars } & \multirow{2}{*}{$\begin{array}{l}\text { Egg-to-adult } \\
\text { period }\end{array}$} \\
\hline & & $2^{\text {nd }}$ & $3^{\text {rd }}$ & $4^{\text {th }}$ & $5^{\text {th }}$ & \\
\hline \multicolumn{7}{|c|}{ Average duration (days) } \\
\hline STANDARD & $6.0 \pm 0.1 \mathrm{~B}$ & $6.0 \pm 0.1 \mathrm{~B}$ & $3.5 \pm 0.1 \mathrm{C}$ & $4.7 \pm 0.1 \mathrm{C}$ & $8.1 \pm 0.2 \mathrm{~B}$ & $31.4 \pm 0.3 \mathrm{~B}$ \\
\hline SOYBEAN & $5.9 \pm 0.1 \mathrm{~B}$ & $7.1 \pm 0.1 \mathrm{AB}$ & $4.3 \pm 0.1 \mathrm{ABC}$ & $5.4 \pm 0.1 \mathrm{BC}$ & $8.5 \pm 0.3 \mathrm{AB}$ & $34.2 \pm 0.3 \mathrm{~A}$ \\
\hline PEANUT & $6.7 \pm 0.1 \mathrm{AB}$ & $7.7 \pm 0.2 \mathrm{~A}$ & $4.9 \pm 0.4 \mathrm{~A}$ & $6.1 \pm 0.2 \mathrm{AB}$ & $8.1 \pm 0.4 \mathrm{~B}$ & $36.6 \pm 0.8 \mathrm{~A}$ \\
\hline SUNFLOWER & $6.3 \pm 0.3 \mathrm{~B}$ & $7.0 \pm 0.5 \mathrm{AB}$ & $4.7 \pm 0.1 \mathrm{AB}$ & $4.9 \pm 0.1 \mathrm{C}$ & $8.1 \pm 0.2 \mathrm{~B}$ & $34.1 \pm 0.7 \mathrm{~A}$ \\
\hline PEA & $7.6 \pm 0.6 \mathrm{~A}$ & $6.7 \pm 0.4 \mathrm{AB}$ & $4.8 \pm 0.2 \mathrm{AB}$ & $5.2 \pm 0.4 \mathrm{BC}$ & $9.3 \pm 0.3 \mathrm{AB}$ & $36.5 \pm 0.9 \mathrm{~A}$ \\
\hline SESAME & $6.5 \pm 0.3 \mathrm{AB}$ & $6.4 \pm 0.1 \mathrm{~B}$ & $4.0 \pm 0.1 \mathrm{BC}$ & $7.1 \pm 0.3 \mathrm{~A}$ & $9.5 \pm 0.2 \mathrm{~A}$ & $36.4 \pm 0.5 \mathrm{~A}$ \\
\hline \multicolumn{7}{|c|}{ Viability rate $(\%)$} \\
\hline STANDARD & $84.0 \pm 1.2 \mathrm{~A}$ & $90.3 \pm 1.8 \mathrm{~A}$ & $86.9 \pm 2.3 \mathrm{~A}$ & $88.9 \pm 2.8 \mathrm{AB}$ & $84.5 \pm 4.2 \mathrm{~A}$ & $49.5 \pm 1.7 \mathrm{AB}$ \\
\hline SOYBEAN & $74.7 \pm 5.8 \mathrm{AB}$ & $85.5 \pm 6.0 \mathrm{~A}$ & $69.6 \pm 9.3 \mathrm{~A}$ & $79.5 \pm 5.1 \mathrm{ABC}$ & $93.2 \pm 6.8 \mathrm{~A}$ & $33.9 \pm 3.6 \mathrm{ABC}$ \\
\hline PEANUT & $74.6 \pm 6.4 \mathrm{AB}$ & $91.3 \pm 3.2 \mathrm{~A}$ & $74.7 \pm 9.5 \mathrm{~A}$ & $74.9 \pm 5.7 \mathrm{BC}$ & $90.6 \pm 4.0 \mathrm{~A}$ & $33.54 \pm 1.9 \mathrm{ABC}$ \\
\hline SUNFOWER & $82.7 \pm 6.4 \mathrm{~A}$ & $82.4 \pm 1.9 \mathrm{~A}$ & $93.0 \pm 3.8 \mathrm{~A}$ & $92.2 \pm 2.8 \mathrm{~A}$ & $93.5 \pm 4.2 \mathrm{~A}$ & $54.6 \pm 2.3 \mathrm{~A}$ \\
\hline PEA & $62.4 \pm 5.9 \mathrm{~B}$ & $78.9 \pm 2.3 \mathrm{~A}$ & $85.8 \pm 4.3 \mathrm{~A}$ & $86.9 \pm 1.5 \mathrm{AB}$ & $75.7 \pm 5.7 \mathrm{~A}$ & $27.5 \pm 1.2 \mathrm{C}$ \\
\hline SESAME & $80.7 \pm 2.4 \mathrm{~A}$ & $87.0 \pm 0.8 \mathrm{~A}$ & $80.0 \pm 6.4 \mathrm{~A}$ & $65.9 \pm 3.6 \mathrm{C}$ & $86.7 \pm 5.2 \mathrm{~A}$ & $32.4 \pm 2.1 \mathrm{BC}$ \\
\hline
\end{tabular}

The mean values $( \pm$ SEM) in a column that are followed by the same letter did not significantly differ according to Tukey's test $(\mathrm{P}<0.05)$. The original data of percent are shown. To perform the analyses, the average percentages were transformed in $\operatorname{arcsen} \sqrt{x} / 100$.

The standard diet leads to the shortest egg-to-adult development period. Stink bugs fed this diet data obtained in the experiments of, mortality caused by the fungi (in each diet-treatment group and among the diet-treatment groups) and the length of the germ tubes were analyzed by ANOVA, comparing means by Scott-Knott's test $(\mathrm{P}<0.05)$. The parameters in the fertility life tables were obtained using the Jackknife method, and the SAS/STAT program was used for comparisons of biological parameter by Tukey's test $(\mathrm{P}<0.05)$ (Maia et al. 2006).

\section{RESULTS}

\section{Comparative biology of $E$. heros fed different natural diets}

Our results indicated that the stink bug diet affected biological parameters in all phases of the stink-bug life cycle.

During the egg phase, the pea diet resulted in a longer hatching period compared with the standard, soybean and sunflower diets. The pea diet also resulted in the lowest egg viability (62.4\%). This value was much lower than that of the standard-, sunflower- and sesame-diet groups (greater than $80 \%$ ).

Differences in the treatment groups were observed during the nymph phase, and the standard- and soybean-diet groups demonstrated the best outcomes, including the shortest development time and the highest viability (Tables 1). 
the other diets required up to five days more than standard diet to insects complete their life cycles (Table 1). Regarding viability throughout the entire cycle, the sunflower diet lead to the highest values, i.e., approximately $55 \%$. The pea and sesame diets lead to the lowest viabilities, $27.5 \%$ and $32.4 \%$, respectively (Table 1 ).

Regarding the adult-phase parameters, the pea diet reduced female fecundity, leading to the oviposition of only 164 eggs within 40 days (Table 2). No significant differences were observed among the other treatment groups, which produced more than the twice the number of eggs of the pea-diet group. The pea-diet group also had the highest percentage of deformed adults. Approximately $11 \%$ of these insects had some type of aberration of their legs and/or wings. In the group treated with the sunflower diet, the prevalence of deformed adults was approximately $5.7 \%$. In the groups treated with the other diets, the prevalence of deformed adults was less than $2.5 \%$ (Table 2). The sunflower-, peaand sesame-diet groups had significant different sex ratios. Insects treated with these diets had a significantly higher ratio of males than did those treated with the standard, soybean or peanut diets. Evaluation of newly emerged adults demonstrated that the sunflower and pea diets resulted in males with the highest average weight. However, the sesame diet resulted in males $(64.7 \mathrm{mg})$ with the lowest average weight. The other diets resulted in intermediate weights that were not significantly different. The sesame diet also resulted in adult females with the lowest average weight $(66.8 \mathrm{mg})$. This value was lower than those obtained using the standard, soybean and peanut diets. The sunflowerand pea-diet groups did not have significantly different results (Table 2).

Table 2. Number of eggs produced, percentage of deformed adults, sex ratio, average weight of the adult males and females of Euschistus heros reared on different natural diets under laboratory conditions $\left(26 \pm 2^{\circ} \mathrm{C}\right.$; $\mathrm{RH}: 60 \pm 10 \%$; photoperiod: 14 hours).

\begin{tabular}{|c|c|c|c|c|c|}
\hline \multirow{2}{*}{ Diet } & \multirow{2}{*}{$\begin{array}{c}\mathrm{N}^{\circ} \text { of Eggs } \\
(40 \text { days })\end{array}$} & \multirow{2}{*}{$\begin{array}{l}\text { Deformed } \\
\text { adults }(\%)\end{array}$} & \multirow{2}{*}{ Sex ratio $^{1}$} & \multicolumn{2}{|c|}{ Weight (mg) } \\
\hline & & & & Males & Females \\
\hline STANDARD & $348.2 \pm 31.3 \mathrm{~A}$ & $1.9 \%$ & $0.506 \mathrm{~A}$ & $73.9 \pm 2.2 \mathrm{AB}$ & $83.7 \pm 2.3 \mathrm{~A}$ \\
\hline SOYBEAN & $343.1 \pm 34.5 \mathrm{~A}$ & $1.2 \%$ & $0.524 \mathrm{~A}$ & $74.1 \pm 2.1 \mathrm{AB}$ & $82.6 \pm 2.6 \mathrm{~A}$ \\
\hline PEANUT & $379.4 \pm 41.1 \mathrm{~A}$ & $2.4 \%$ & $0.473 \mathrm{~A}$ & $73.5 \pm 2.3 \mathrm{AB}$ & $82.1 \pm 2.7 \mathrm{~A}$ \\
\hline SUNFLOWER & $379.1 \pm 32.5 \mathrm{~A}$ & $5.7 \%$ & $0.404 \mathrm{~B}$ & $74.4 \pm 2.7 \mathrm{~A}$ & $74.3 \pm 2.9 \mathrm{AB}$ \\
\hline PEA & $163.6 \pm 35.8 \mathrm{~B}$ & $10.8 \%$ & $0.457 \mathrm{~B}$ & $75.2 \pm 2.1 \mathrm{~A}$ & $77.1 . \pm 3.1 \mathrm{AB}$ \\
\hline SESAME & $386.2 \pm 45.4 \mathrm{~A}$ & $1.9 \%$ & $0.451 \mathrm{~B}$ & $64.7 \pm 2.2 \mathrm{~B}$ & $66.8 \pm 4.2 \mathrm{~B}$ \\
\hline
\end{tabular}

The mean values $( \pm$ SEM) in a column that are followed by the same letter did not significantly differ according to Tukey's test $(\mathrm{P}<0.05) .{ }^{1} \mathrm{n}^{\circ}$ of female/( $\mathrm{n}^{\circ}$ of male $+\mathrm{n}^{\circ}$ of female). $N$ to Deformed adults and Sex ratio: 163 (Standard); 184 (Soybean); 185 (Peanut); 123 (Sunflower); 86 (Pea); 104 (Sesame).

The results shown in the life and fertility table (Table 3) corroborated the results obtained for the life stages of the stink bugs. The standard diet lead to the best results for all of the analyzed parameters, and the pea and sesame diets always lead to the worst results. Notably, the soybean and sunflower diets did not significantly change the values for any of the analyzed parameters.

The net reproductive rate (Ro) for insects treated with the standard and sunflower diets was almost three times higher than that of the insects treated with the pea diet. The soybean and peanut diets lead to the highest rates, and a significant difference was not observed in the sesame-diet group. The duration of one generation ( $\mathrm{T}$ ) was less than 51 days for the insects treated with the standard diet. The longest duration was that of insects treated with the sesame or peanut diets. The generation periods of stink bugs treated with these two diets were 63 and 61 days, respectively. The duplication time (DT) was less than eight days for insects treated with the standard diet. The DT was more than twelve days for the pea-diet group and almost eleven days for the sesame-diet group. These two diets lead to the worst outcome for this parameter. The intrinsic rate of increase $(\mathrm{rm})$ for insects fed the standard diet (0.0877) was higher than that of the pea- or sesamediet groups. The latter diets resulted in the lowest observed values. The same trend was observed for the finite rate of increase $(\lambda)$. The highest values were those of the standard-diet group (1.0917), followed by soybean (1.0771), sunflower (1.0768), peanut (1.0714), and sesame (1.0655) diet groups. The lowest observed value was that of the pea-diet group (1.0581) (Table 3). 
Table 3. Values for the life parameters of Euschistus heros reared on different natural diets under laboratory conditions (26 $\pm 2^{\circ} \mathrm{C}$; RH: $60 \pm 10 \%$; photoperiod: 14 hours) (obtained by Jackknife method).

\begin{tabular}{llllcc}
\hline \multirow{2}{*}{ Diet } & \multicolumn{5}{c}{ Parameter $^{1}$} \\
\cline { 2 - 6 } & \multicolumn{1}{c}{ Ro } & \multicolumn{1}{c}{$\mathrm{T}$} & $\mathrm{TD}$ & $\mathrm{rm}$ & $\lambda$ \\
\hline STANDARD & $87.02 \mathrm{~A}$ & $50.87 \mathrm{D}$ & $7.89 \mathrm{E}$ & $0.0877 \mathrm{~A}$ & $1.0917 \mathrm{~A}$ \\
SOYBEAN & $66.01 \mathrm{AB}$ & $56.36 \mathrm{C}$ & $9.32 \mathrm{D}$ & $0.0743 \mathrm{~B}$ & $1.0771 \mathrm{~B}$ \\
PEANUT & $69.98 \mathrm{AB}$ & $61.58 \mathrm{AB}$ & $10.04 \mathrm{C}$ & $0.0689 \mathrm{C}$ & $1.0714 \mathrm{C}$ \\
SUNFLOWER & $84.91 \mathrm{~A}$ & $59.98 \mathrm{BC}$ & $9.36 \mathrm{D}$ & $0.0740 \mathrm{~B}$ & $1.0768 \mathrm{~B}$ \\
PEA & $27.82 \mathrm{C}$ & $58.85 \mathrm{BC}$ & $12.26 \mathrm{~A}$ & $0.0561 \mathrm{E}$ & $1.0581 \mathrm{E}$ \\
SESAME & $57.35 \mathrm{~B}$ & $63.74 \mathrm{~A}$ & $10.91 \mathrm{~B}$ & $0.0635 \mathrm{D}$ & $1.0655 \mathrm{D}$ \\
\hline
\end{tabular}

The mean values $( \pm$ SEM) in a column that are followed by the same letter did not significantly differ according to Tukey's test $(\mathrm{P}<0.05) .{ }^{1}$ Net reproduction rate $($ Ro); duration of one generation $(\mathrm{T})$, duplication time (DT); intrinsic rate of increase $(\mathrm{rm})$; and, finite rate of increase $(\lambda)$.

\section{Effect of diet on the susceptibility of $E$. heros to fungi}

In each diet-treatment group, only insects fed the sesame diet had significantly different sensitivity for B. bassiana and M. anisopliae $(\mathrm{F}=227.8$; C.V. $=11.6 ; \mathrm{P}<0.0001)$. The $M$. anisopliae Unioeste 22 strain was more virulent (55\% mortality) than was the B. bassiana Unioeste 46 strain (40\% mortality) (Table 4). For the other diets, the mortality caused by these two strains of fungi did not differ. These results showed equivalence of the activities of the isolates at the concentrations used in our experiments.

Table 4. Confirmed mortality (\%) of Euschistus heros reared on each natural diet caused by Beauveria bassiana (Unioeste 46) or Metarhizium anisopliae (Unioeste 22) under laboratory conditions $\left(26 \pm 2^{\circ} \mathrm{C} ; \mathrm{RH}\right.$ : $60 \pm 10 \%$; photoperiod: 14 hours).

\begin{tabular}{lcrl}
\hline \multirow{2}{*}{ Diet $^{1}$} & \multicolumn{3}{c}{ Treatment } \\
\cline { 2 - 4 } & B. bassiana & M. anisopliae & Control \\
\hline STANDARD & $48.3 \pm 2.7 \mathrm{~A}$ & $43.3 \pm 4.0 \mathrm{~A}$ & $0.0 \pm 0.0 \mathrm{~B}$ \\
SOYBEAN & $41.7 \pm 1.1 \mathrm{~A}$ & $35.0 \pm 3.2 \mathrm{~A}$ & $0.0 \pm 0.0 \mathrm{~B}$ \\
PEANUT & $61.7 \pm 2.0 \mathrm{~A}$ & $63.3 \pm 3.7 \mathrm{~A}$ & $0.0 \pm 0.0 \mathrm{~B}$ \\
SUNFLOWER & $53.3 \pm 2.9 \mathrm{~A}$ & $51.7 \pm 2.7 \mathrm{~A}$ & $0.0 \pm 0.0 \mathrm{~B}$ \\
PEA & $57.5 \pm 3.9 \mathrm{~A}$ & $52.5 \pm 1.6 \mathrm{~A}$ & $0.0 \pm 0.0 \mathrm{~B}$ \\
SESAME & $40.0 \pm 2.6 \mathrm{~B}$ & $55.0 \pm 1.8 \mathrm{~A}$ & $0.0 \pm 0.0 \mathrm{C}$ \\
\hline
\end{tabular}

The mean values $( \pm \overline{\mathrm{SEM}})$ in a row that are followed by the same letter did not significantly differ according to ScottKnott's test $(\mathrm{P}<0.05)$. To perform the analyses, the average percentages were transformed using $\operatorname{arcsen} \sqrt{\mathrm{x}} / 100$.

${ }^{1}$ STANDARD: Bean pods plus peanuts, soybeans and sunflower seeds; SOYBEAN: Bean pods plus soybeans; PEANUT: Bean pods plus peanuts; SUNFLOWER: Bean pods plus sunflower seed; PEA: Bean pods plus peas; SESAME: bean pods plus sesame seeds.

In another bioassay comparing the mortality caused by each strain in the different diet groups, we found that diet affected mortality. We observed significant differences among the diet groups for total mortality $(\mathrm{F}=16.1 ; \mathrm{C} . \mathrm{V} .=17.3 ; \mathrm{P}<0.0001)$ and confirmed mortality (corpses with signs of fungal infection $)(\mathrm{F}=43.6 ; \mathrm{C} . \mathrm{V} .=14.4 ; \mathrm{P}<0.0001)$ caused by $B$. bassiana; and total mortality (mortality with signs and no signs of fungal infection $)(\mathrm{F}=10.8 ; \mathrm{C}$. $\mathrm{V} .=20.4 ; \mathrm{P}<0.0001)$ caused by $M$. anisopliae (Table 5). The difference in confirmed mortality by M. anisopliae $(\mathrm{F}=34.8 ; \mathrm{C} . \mathrm{V} .=15.3 ; \mathrm{P}<0.0001)$ among the diet groups was not significant (Table 5).

Table 5: Total and confirmed mortality (\%) caused by Beauveria bassiana (Unioeste 46) or Metarhizium anisopliae (Unioeste 22) among Euschistus heros reared on different natural diets under laboratory conditions $\left(26 \pm 2^{\circ} \mathrm{C}\right.$; RH: $60 \pm 10 \%$; photoperiod: 14 hours).

$$
\text { Diet }^{1} \text { \% Mortality }
$$




\begin{tabular}{|c|c|c|c|c|}
\hline & \multicolumn{2}{|c|}{ Beauveria bassiana } & \multicolumn{2}{|c|}{ Metarhizium anisopliae } \\
\hline & Total & Confirmed & Total & Confirmed \\
\hline CONTROL & $6.3 \pm 1.3 \mathrm{C}$ & $0.0 \pm 0.0 \mathrm{C}$ & $6.7 \pm 1.2 \mathrm{C}$ & $0.0 \pm 0.0 \mathrm{~B}$ \\
\hline STANDARD & $25.0 \pm 3.0 \mathrm{~B}$ & $16.7 \pm 2.2 \mathrm{~B}$ & $\begin{array}{c}52.1 \pm 7.5 \\
\text { B }\end{array}$ & $50.0 \pm 2.2 \mathrm{~A}$ \\
\hline SOYBEAN & $52.1 \pm 3.9 \mathrm{~A}$ & $37.5 \pm 1.5 \mathrm{~A}$ & $\begin{array}{c}81.3 \pm 2.5 \\
\mathrm{~A}\end{array}$ & $52.1 \pm 1.32 \mathrm{~A}$ \\
\hline PEANUT & $52.1 \pm 3.3 \mathrm{~A}$ & $31.3 \pm 2.5 \mathrm{~A}$ & $\begin{array}{c}85.4 \pm 4.5 \\
\mathrm{~A}\end{array}$ & $54.2 \pm 2.6 \mathrm{~A}$ \\
\hline SUNFLOWER & $52.1 \pm 4.5 \mathrm{~A}$ & $35.4 \pm 3.3 \mathrm{~A}$ & $\begin{array}{c}70.8 \pm 9.3 \\
\mathrm{~A}\end{array}$ & $58.3 \pm 5.7 \mathrm{~A}$ \\
\hline PEA & $39.6 \pm 2.5 \mathrm{~A}$ & $27.1 \pm 1.3 \mathrm{~A}$ & $\begin{array}{c}58.3 \pm 3.0 \\
\text { B }\end{array}$ & $47.5 \pm 2.6 \mathrm{~A}$ \\
\hline SESAME & $60.4 \pm 2.5 \mathrm{~A}$ & $41.7 \pm 2.2 \mathrm{~A}$ & $\begin{array}{c}87.5 \pm 3.4 \\
\mathrm{~A}\end{array}$ & $47.9 \pm 3.9 \mathrm{~A}$ \\
\hline
\end{tabular}

The mean values $( \pm$ SEM) in a column that are followed by the same letter did not significantly differ according to the Scott-Knott's test $(\mathrm{P}<0.05)$. To perform the analyses, the average percentages were transformed using $\operatorname{arcsen} \sqrt{\mathrm{x}} / 100$.

${ }^{1}$ STANDARD: Bean pods plus grains of peanut, soybean and sunflower; SOYBEAN: Bean pods plus peanuts, soybeans and sunflower seeds; SOYBEAN: Bean pods plus soybeans; PEANUT: Bean pods plus peanuts; SUNFLOWER: Bean pods plus sunflower seed; PEA: Bean pods plus peas; SESAME: bean pods plus sesame seeds.

Statistical analysis of total and confirmed mortality caused by $B$. bassiana demonstrated the same tendency of results. In the standard treatment, the total and confirmed mortality were 25 and $16.7 \%$, respectively. Insects maintained on a soybean, peanut, sunflower or sesame diet had higher mortality than those on the standard diet. Among these others diets groups the mortalities values were not significantly different.

The highest total mortality rates for $M$. anisopliae were observed in the sesame- $(87.5 \%)$, peanut(85.4\%), soybean- $(81.3 \%)$ and sunflower- $(70.8 \%)$ diet groups, which the difference was not significant from each other. The standard and pea diet produced the less susceptible insects, with mortality values of $52.1 \%$ and $58.3 \%$, respectively. For confirmed mortality the values varied among $47.5-58.3 \%$ in treatment groups, not being significantly different (Table 5).

\section{Germination on $E$. heros wings}

The wings of stink bugs maintained on each of natural diets were used as substrates for the germination of fungi. The length of the conidial germ tubes of both fungi was affected by the treatments (Figs. 1 and 2).

$B$. bassiana formed longer germ tubes when inoculated on the wings of insects reared on the standard, soybean and peanut diet compared with those reared on the sunflower, pea and sesame diets $(\mathrm{F}=5.9 ;$ C.V. 10.1; $\mathrm{P}=0.0003)$, which delayed the growth of this fungus (Fig. 1).

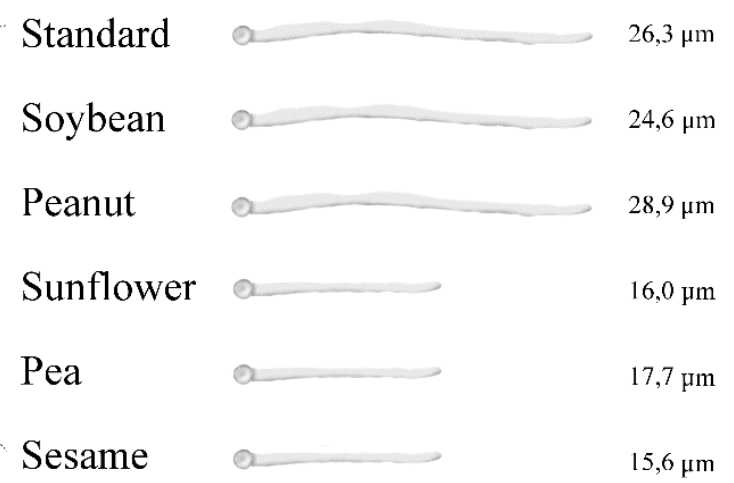

Figure. 1. Length $(\mu \mathrm{m})$ of Beauveria bassiana (Unioeste 46) germ tubes that formed on the hind wings of Euschistus heros reared on different natural diets after 24 hours of incubation $\left(26 \pm 2{ }^{\circ} \mathrm{C} ; 90 \pm 10 \% \mathrm{RU}, 14\right.$-hour photoperiod $)$. Germ tubes of the same size did not significantly differ according to Scott-Knott's test $(\mathrm{P}<0.05)$. 
The germ tubes of $M$. anisopliae that formed on the wings of insects fed standard, peanut and sesame diets were significantly longer than those of fed on the soybean, sunflower and pea diets. The latter diets negatively affected $M$. anisopliae development $(\mathrm{F}=7.5 ; \mathrm{C} . \mathrm{V} .=7.5 ; \mathrm{P}<0.0001)$ (Fig. 2).

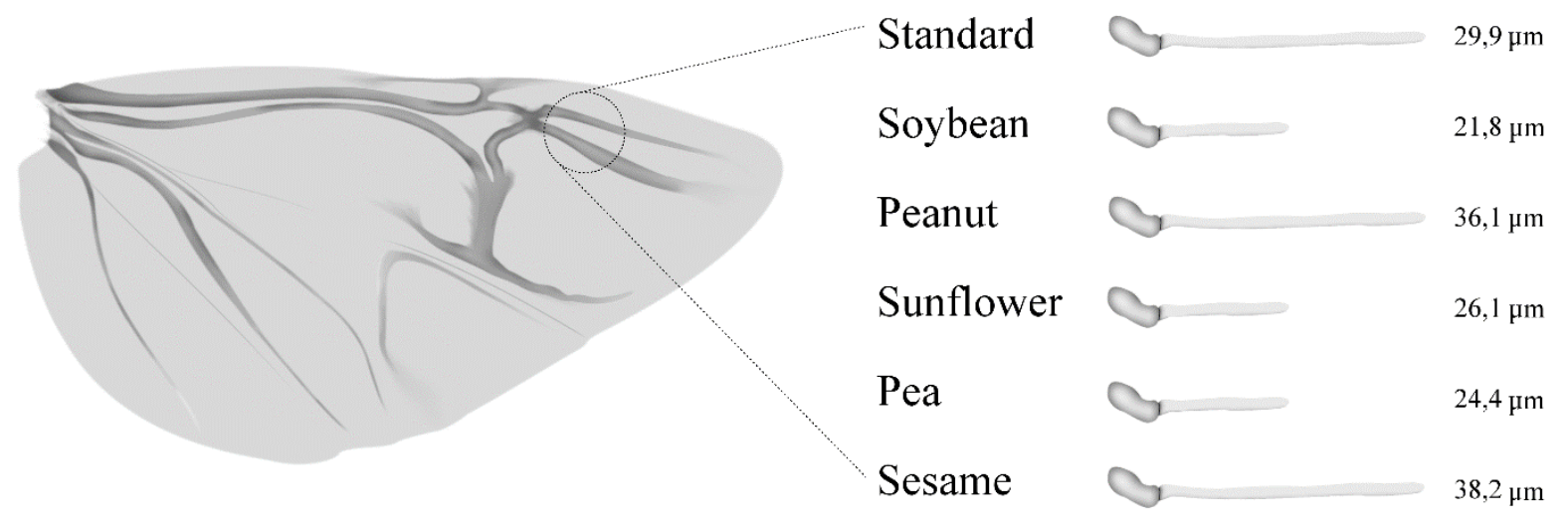

Figure. 2. Length $(\mu \mathrm{m})$ of the Metarhizium anisopliae (Unioeste 22) germ tubes that formed on the hind wings of Euschistus heros reared on different natural diets after 24 hours of incubation $\left(26 \pm 2{ }^{\circ} \mathrm{C} ; 90 \pm 10 \%\right.$ RU, 14-hour photoperiod). Germ tubes of the same size did not significantly differ according to Scott-Knott's test $(\mathrm{P}<0.05)$.

\section{DISCUSSION}

The results of this study demonstrated the importance of diet for the development of E. heros and the relationship between the nutritional status of these stink bugs and their susceptibility to infections of the entomopathogenic fungi $B$. bassiana and M. anisopliae.

Regarding the effect of diet on the biological parameter of the stink bugs, it is well known that reproduction, survival and the development of the insects are heavily influenced by the alimentary source exploited (Panizzi et al. 1991). According to our data, a restrictive diet (containing 1 type of grain exclusively) negatively affected the biological parameters of E. heros. All of these restricted diets caused an extension in time of development egg-toadult period compared with the standard diet. Panizzi et al. (2009) report that phytophagous insects fed inadequate diets (those lacking in nutrients) extend their development period to store the energy and nutritional reserves necessary for the changes in the life stages. The diversity of grains in the standard diet evaluated provided better conditions for the development of the stink bugs. In fact, this diet was always the one that resulted in the shortest duration of the life stages, better viability, higher fecundity and fertility and a better index in the life table.
Similar results were obtained by Azambuya et al. (2013), who compared the natural standard diet of E. heros (bean pods, peanut grains and privet fruits) to restrictive diets containing only parts of plants (soybean pods, soybean seeds, cotton floral buds, cotton bolls or cotton seeds). The authors reported that the standard diet (which provided a variety of nutritional resources) is among the best for the development of stink bugs regarding all considered parameters.

Insects require a qualitative and quantitative balance among the nutrients provided. Alterations in the biological parameters, such as those that were observed in the insects fed the restrictive diets tested in this study, support this concept. As an example, the sunflower diet, which lead to excellent results for some parameters (viability, weight of the males, liquid reproduction rate), was associated with higher rates of deformities in adults, which is most likely caused by a qualitative unbalance in the provided nutrients (Parra 2010). If we examine the nutritional quality of seeds used (table of nutritional composition Unicamp-NEPA 2011), we observe that the sunflower diet has a low concentration of proteins and carbohydrates (less than 20\% and $17 \%$, respectively), and high concentration of lipids (approximately 50\%). In contrast, the soybean diet contains equivalent quantities of carbohydrates (more than 38\%) and proteins (more than 36\%) and 
a low concentration of lipids (less than 15\%). The peanut diet contains over $46 \%$ lipids and low concentrations of carbohydrates (20\%) and proteins (less than 27\%). The sesame diet also contains a high percentage of lipids (40\%) and low concentrations of carbohydrates (10\%) and proteins $(20 \%)$. All of these grains have high energetic values (over $400 \mathrm{Kcal} / 100 \mathrm{~g}$ portion). The pea diet has a low energetic value and few available nutrients $(74 \mathrm{Kcal} / 100 \mathrm{~g}$; less than $13 \%$ carbohydrates, $5 \%$ proteins and $1 \%$ fats). These data corroborate the results of our experiments and those of Azambuja et al. (2013). Having a variety of grains in the diet provided the stink bugs different quantities and qualities of nutritional resources. This variety of resources has a positive effect on the development of the insects, as observed by studying biological parameters. Nutritional deficiencies also explain why the worst results were obtained in the pea treatment group. The nutritional elements available in this grain are insufficient for the adequate development of stink bugs, especially as the only food source. Water is another important element to be considered, because all grains have a water concentration below $7 \%$. It is therefore essential to always provide fresh bean pods, since his concentration of water is greater than $90 \%$.

The plant species upon which phytophagous insects feed can (positively or negatively) affect not only their biological functions but also those of their enemies. The effect of feed on pathogens may be direct or indirect due to the existence of a complex network of multitrophic interactions (Legaspi et al. 1996; Silva et al. 2004). To better understand this premise, the interactions among insect pests, their natural enemies and their host plants must be intensely studied. For example, susceptibility may be affected by components of the insect cuticle, seeing that conidia may suffer from toxicity, fungistatic effects and eventual stimulating effects (Sosa-Gómez et al. 1997; Gillespie et al. 2000; Santiago-Alvarez et al. 2006) by compounds in the cuticle of the insects, those sequestrated from alimentary sources (Tallamy et al. 1998), or even through volatiles produced by metathoracic glands (Lopes et al. 2015). This effect has been demonstrated for fungi (Nishida et al. 1992; Tallamy et al. 1998; Poprawski et al. 2000a; Poprawski et al. 2000b; Klingen et al. 2002).

The first phases of the fungi infective process, i.e., adhesion, germination, the formation of invasive structures and the beginning of penetration, all occur on the cuticle. The conditions encountering pathogens on the surface of cuticles may strongly affect the beginning of this process, and as a consequence, the later stages of disease development (Hajek et al., 1994; Ortiz-Urquiza et al., 2013). Germination assays demonstrated that dietary modifications have significant effects on the germination of the B. bassiana and M. anisopliae. It was verified the size of the germ tubes of both fungi significantly changed according to the host's diet. The wings of insects fed the standard and peanut diets always exhibited the greatest germ tube development to both fungi. In contrast the sunflower and pea diets had a negative effect on the growth of germ tubes. The results for the soybean diet were variable in this study. No evidence of a relationship between germ tube growth and the mortality rates was determined here, but is noteworthy that insects fed this diet always had the one of the longest germ tube growth for $M$. anisopliae and, at the same time, negatively affected the growth of $B$. bassiana germ tubes. Possibly some factors associated with the cuticles of the stink bugs reared on the sesame diet adversely affected the conidia of $B$. bassiana but not those of $M$. anisopliae.

Despite the differential cuticle effect on germination of fungi have been demonstrated, possibly other factors are more important in the establishment of $B b$ and $M a$ infection on Euschistus heros. In the comparative assay (each strain in the different diet groups) was clearly demonstrated that the insect nutritional condition was decisive in the susceptibility to fungi. Generally, some studies have demonstrated an effect of insect nutrition on their predators (Kennedy 2003), parasitoids (Harvey et al. 1995) and their pathogens (Salama et al. 1992; Poprawsky et al. 2000a; Santiago-Alvarez et al. 2006). Regarding the entomopathogenic fungi, the nutritional status of insects greatly affected disease development (Shah et al. 2005; Sosa-Gomez 2012), and the nutritional stress may increase the susceptibility of insects to fungi (Santiago-Alvarez et al. 2006; Lord 2010).

In the present work, the standard diet had no negative effect on germ tube growth although insects maintained on this diet were less susceptible to both of the fungi (total and confirmed mortality to $B b$; total mortality to $M a$ ), which could be due to better nutritional status compared with the restricted diets. This observation was confirmed by biological parameter data, and other authors also reported the effects of nutrition on the susceptibility 
of insects to entomopathogenic fungi (Lord 2010; Santiago-Alvarez et al. 2006). These authors reported that mortality was significantly affected by the host plants and that the diet affected the susceptibility to infection, the survival time and the production of conidia in cadavers, proving that insects fed better quality diets are less susceptible to $B$. bassiana infections agents.

The nutritional status of the fungi before the infection process must also be considered to understanding the host-pathogen relationship (James 2001; Rangel et al. 2008). In our experiments, all conidia of both fungi were grown from the same kind of culture medium. Therefore, the development of infection was affected only by the cuticle and the nutritional status of the hosts, observing the effects of the latter in susceptibility to fungi.

We did not investigate the presence or the type of antifungal compounds in the cuticles of the stink bugs; however, based on observations, such studies are very important. These data may facilitate understanding how the differences among the diets examined in this study affect the composition of the cuticles of E. heros and contribute to the knowledge of the multitrophic relationships between pathogens and insect pests.

\section{CONCLUSIONS}

Thus, we conclude that the standard diet composed of bean pods combined with soybeans, peanuts and sunflower produced adults with the best biological characteristics and less susceptible to both entomopathogenic fungal species compared to the insects from the other diets (containing 1 type of grain exclusively). Our results contribute to the knowledge concerning the interactions among pathogens, pest insects and diet.

\section{REFERENCES}

Alves SB, Moraes AS. Quantificação de inoculo de patógenos de insetos. p. 765-777. In: Alves SB, editor. Controle Microbiano de Insetos. Piracicaba, FEALQ, 1998, 1163p.

Azambuja R, Degrande PE, Pereira FF. Comparative biology of Euschistus heros (F.) (Hemiptera: Pentatomidae) feeding on cotton and soybean reproductive structures.- Neotrop Entomol. 2013; 42: 359-365.

Corrêa-Ferreira BS. Suscetibilidade da soja a percevejos na fase anterior ao desenvolvimento das vagens. Pesq Agropec Bras, 2005; 40: 1067-1072.
Cory JS, Myers, JH. Adaptation in an insect host-plant pathogen interaction. Ecol Lett. 2004; 7: 632-639.

Gillespie JP, Bailey AM, Cobb B, Vilcinskas A. Fungi as elicitors of insect immune responses. Arch Insect Biochem. 2000; 44: 49-68.

Hajek AE, St Leger RJ. Interaction between fungal pathogens and insect hosts. Annu Rev Entomol. 1994; 39: 293-322.

Harvey JA, Harvey IF, Thompson DJ. The effect of host nutrition on growth and development of the parasitoid wasp Venturia canescens. Entomol Exp Appl. 1995; 75: 213-220.

Ihara F, Toyama M, Mishiro K, Yaginuma K. Laboratory studies on the infection of stink bugs with Metarhizium anisopliae strain FRM515. Appl Entomol Zool. 2008; 43: 503-509.

James RR. Effects of exogenous nutrients on conidial germination and virulence against the Silverleaf Whitefly for two hyphomycetes. J Invert Pathol. 2001; 77: 99-107.

Kennedy GG. Tomato, pests, parasitoids, and predators: Tritrophic interactions involving the genus Lycopersicon. Annu Rev Entomol. 2003; 48: 51-72.

Klingen I, Hajek A, Meadow R, Renwick JAA. Effect of brassicaceous plants on the survival and infectivity of insect pathogenic fungi. BioControl. 2002; 47: 411425.

Legaspi JC, Nordlund DA, Legaspi Jr BC. Tri-trophic interactions and predation rates in Chrysoperla spp. attacking the silverleaf whitefly. Southwest Entomol. 1996; 21: 33-42.

Lopes RB, Laumann RA, Blassioli-Moraes MC, Borges M, Faria M. The fungistatic and fungicidal effects of volatiles from metathoracic glands of soybeanattacking stink bugs (Heteroptera: Pentatomidae) on the entomopathogen Beauveria bassiana. J Invert Pathol. 2015; 132: 77-85.

Lord JC. Dietary stress increases the susceptibility of Tribolium castaneum to Beauveria bassiana. J Econ Entomol. 2010; 103: 1542-1546.

Maia AHN, Luiz AJB. Programa SAS para análise de tabelas de vida e fertilidade de artrópodes: o método Jackknife. Comunicado Técnico 33. Embrapa: Jaguariúna. 2006. 11p.

Moscardi F, Corrêa-Ferreira BS, Villas Boas GL, Leite LG, Zamataro CE. Avaliação de fungos entomógenos sobre percevejos-pragas da soja, em laboratório. In: Resultados de Pesquisa de Soja 1984-1985. EMBRAPA - Centro Nacional de Pesquisa de Soja, Londrina, PR, Brasil. 1985. p. 91-98.

Moscardi F, Corrêa-Ferreira BS, Diniz MC, Bono ILS. Incidência estacional de fungos entomógenos sobre populações de percevejos-pragas da soja. In: Resultados de Pesquisa de Soja 1986-1987. EMBRAPA - Centro Nacional de Pesquisa de Soja, Londrina, PR, Brasil. 1988. p. 90.

Nishida R, Yokoyama M, Fukami H. Sequestration of cucurbitacin analogs by new and old world 
chrysomelid leaf beetles in the tribe Luperini. Chemoecol. 1992; 3: 19-24.

Oliveira DGP, Pauli G, Mascarin GM, Delalibera I. A protocol for determination of conidial viability of the fungal entomopathogens Beauveria bassiana and Metarhizium anisopliae from commercial products. $J$ Microbiol Meth. 2015; 119, 44-52.

Ortiz-Urquiza A, Keyhani NO. Action on the surface: Entomopathogenic fungi versus the insect cuticle. Insects. 2013; 4: 357-374.

Panizzi AR. History and contemporary perspectives of the integrated pest management of soybean in Brazil. Neotrop Entomol. 2013; 42: 119-127.

Panizzi AR, Slansky JRF. Suitability of selected legumes and the effect of nymphal and adult nutrition in the southern green stink bug (Hemiptera: Heteroptera: Pentatomidae).- J Econ Entomol. 1991; 84: 103-113.

Panizzi AR, Silva FAC. Insetos sugadores de sementes (Heteroptera). In: Bioecologia e nutrição de insetos: base para o manejo integrado de pragas. Panizzi AR, Parra JRP. editors. Embrapa Informação Tecnológica, 2009. p.465-522.

Parra JRP. Técnicas de criação de insetos para programas de controle biológico. USP/ESALQ. 2010. 567p.

Poprawski TJ, Jones WJ. Host plant effects on activity of the mitosporic fungi Beauveria bassiana and Paecilomyces fumosoroseus against two populations of Bemisia whiteflies (Homoptera: Aleyrodidae). Mycopathol. 2000; 151: 11-20a.

Poprawski TJ, Greenberg SM, Ciomperlik MA. Effect of host plant on Beauveria bassiana and Paecilomyces fumosoroseus induced mortality of Trialeurodes vaporariorum (Homoptera: Aleyrodidae).- Environ Entomol. 2000; 29: 1048-1053b.

Rangel DEN, Alston DG, Roberts DW. Effects of physical and nutritional stress conditions during mycelial growth on conidial germination speed, adhesion to host cuticle, and virulence of Metarhizium anisopliae, an entomopathogenic fungus. Mycol Res. 2008; 112: 1355-1361.

Salama HS, Abedel-Razek A. Effect of different kinds of food on susceptibility of some stored products insects to Bacillus thuringiensis. J Appl Entomol. 1992; 113: 107-10.

Santiago-Álvarez C, Maranhão EA, Maranhão E, Quesada-Moraga E. Host plant influences pathogenicity of Beauveria bassiana to Bemisia tabaci and its sporulation on cadavers. BioControl. 2006; 51: 519-32.

Sas Institute. SAS/STAT. User's Guide. Version 9.1.3, Cary, NC, USA. 2002/2003.

Silva CC, Laumann RA, Blassioli MC, Pareja M, Borges M. Euschistus heros mass rearing technique for the multiplication of Telenomus podisi. Pes Agropec Bras. 2008; 43: 575-580.

Silva FAS, Azevedo CAV. A New Version of The Assistat-Statistical Assistance Software. (2006) In: World Congress on Computers in Agriculture, 4,
Orlando-FL-USA: Anais... Orlando: American Society of Agricultural and Biological Engineers,. p.393-396.

Silveira Neto S, Nakano O, Barbin D, Villa Nova NA. Manual de ecologia dos insetos. São Paulo, Ceres; 1976. 419p.

Sosa-Gómez DR. Implications of plant hosts and insect nutrition on entomopathogenic diseases. In: Panizzi AR, Parra JRP, editors. Insect bioecology and nutrition for integrated pest management. CRC Press; 2012. p. 195-210.

Sosa-Gómez DR, Silva JJ, Lopes NIO, Corso IC, Almeida AMR, Moraes GCP, Baur ME. Insecticide susceptibility of Euschistus heros (Heteroptera: Pentatomidae) in Brazil. J Econc Entomol 2009; 102: 1209-1216.

Sosa-Gómez DR, Boucias DG, Nation JL. Attachment of Metarhizium anisopliae to the southern green stink bug Nezara viridula cuticle and fungistatic effect of cuticular lipids and aldehydes. J Invert Pathol. 1997; 69: 31-39.

Sosa-Gómez DR, Moscardi F. Laboratory and field studies on the infection of stink bugs, Nezara viridula, Piezodorus guildinii, and Euschistus heros (Hemiptera: Pentatomidae) with Metarhizium anisopliae and Beauveria bassiana in Brazil. J Invert Pathol. 1998; 71: 115-120.

Tallamy DW, Whittington DP, Defurio F, Fontaine DA, Gorski PM, Gothro, PW. Sequestered cucurbitacins and pathogenicity of Metarhizium anisopliae (Moniliales: Moniliaceae) on spotted cucumber beetle eggs and larvae (Coleoptera: Chrysomelidae). Environ Entomol. 1998; 27: 66-372. 
Unicamp-Nepa. Brazilian table of food composition TACO. Campinas, $4^{\mathrm{a}}$ ed., 2011. 161p.

Vilcinskas A, Götz P. Parasitic fungi and their interactions with the insect immune system. $A d v$ Parasit. 1999; 43: 267-313.

Received: March 03, 2016;

Accepted: April 26, 2016 